\title{
Polyvinyl Alcohol as a Useful Indicator on Iodometry: Volumetric and Spectrophotometric Studies on Iodine-PVA and Iodine-Starch Complexes
}

\author{
Tetsutaro Yoshinaga, ${ }^{* \dagger}$ Tomoharu Shirakata, ${ }^{*}$ Hideo Dohtsu, ${ }^{*}$ Hiroshi Hiratsuka, ${ }^{* *}$ \\ Miki HaSegawa, $* * *$ Michio KobayashI, $* * *$ and Toshihiko HoSHI*** \\ *Department of Applied Chemistry, Faculty of Engineering, Kyushu Institute of Technology, \\ Sensuicho, Tobata, Kitakyushu 804-8550, Japan \\ **Department of Chemistry, Faculty of Engineering, Gunma University, \\ Tenjincho, Kiryu, Gunma 376-8515, Japan \\ ***Department of Chemistry, Faculty of Science and Engineering, Aoyamagakuin University, \\ Chitosedai, Setagaya, Tokyo 157-8572, Japan
}

\begin{abstract}
Iodometry is one of the easiest, most rapid and accurate methods for the determination of a relatively small amount of oxidizing agent, such as residual chlorine. Starch has long been used as a useful color indicator in iodometry. However, we found that PVA (polyvinyl alcohol with partially saponificated; e.g., saponification degree of $88 \%$ ) is a more useful color indicator than starch. For example, at $20^{\circ} \mathrm{C}$, the PVA indicator gave similar profiles of iodine concentration $v s$. titration efficiencies (percent recoveries) to those of starch at $0^{\circ} \mathrm{C}$. At $0^{\circ} \mathrm{C}$, the PVA indicator detected $1.1 \mathrm{mg} \mathrm{I} / \mathrm{L}(11 \mu \mathrm{g}$ $\mathrm{I}_{2}$ : with $10 \mathrm{~mL}$ sample volume) with a high percentage of recovery ( $\left.\fallingdotseq 95 \%\right)$. Furthermore, at $20^{\circ} \mathrm{C}$ an iodine concentration of $0.36 \mathrm{mg} / \mathrm{L}$ (which corresponds to a residual chlorine concentration of $0.1 \mathrm{mg} \mathrm{Cl} / \mathrm{L}$ ) could be detected using PVA color indicator assuming an appropriate correction.
\end{abstract}

(Received June 30, 2000; Accepted November 8, 2000)

In heavy industries, such as thermal power stations and atomic power stations operated in coastal industrial zones, a great deal of cooling water is required; usually, coastal seawater is used for this purpose. There are varieties of plankton (e.g., larva of mussels, barnacles (acorn shell), oysters, sea-anemone (Actinia), algae, and many other microbes) in seawater. These marine organisms are adsorbed and grow up on the inner walls of pipes, thus blocking condensers and other pipe lines, and cause a lowering of the thermal conductivities. ${ }^{1-3}$ Chlorine injection is often carried out as a counter measure, with concentrations of around $1 \mathrm{ppm}(=\mathrm{mg} / \mathrm{L})$. For service water, chlorine injections are usually made to protect against infectious disease in Japan, and the residual chlorine concentrations are controlled to be higher than $0.1 \mathrm{ppm}^{4}$ at the outlet of faucets. The residual chlorine concentration is considered preferably be less than $1 \mathrm{ppm}$ at a faucet for a pleasant taste of drinking water. Practically, at the outlet of a clean water reservoir, the residual chlorine concentrations are $1.2-1.3 \mathrm{ppm}$, and at the outlets of faucets they are in the range of $0.1-0.8 \mathrm{ppm}(0.4-0.5 \mathrm{ppm}$ as average). Iodometry is one of the easiest and most accurate methods used to determine the residual chlorine concentration. This method uses starch as color indicator at the end point, utilizing the well-known iodine-starch reaction. For example, according to the Japanese Industrial Standard (testing methods for industrial waste water: JIS K 0101-1998), ${ }^{5}$ the absolute weight measuring range is $0.1-7 \mathrm{mg} \mathrm{Cl}_{2}$, and thus the lower limit concentration has been calculated to be $c a .0 .3 \mathrm{ppm}$ with

$\doteqdot$ To whom correspondence should be addressed.

E-mail: yosinaga@che.kyutech.ac.jp
$300 \mathrm{~mL}$ (maximum) sampling volume; it thus seems impossible to determine a residual chlorine concentration of $0.1 \mathrm{ppm}$. Peat et al. ${ }^{6}$ pointed out the chief disadvantages of starch as a color indicator to be: (1) the insolubility of starch in cold water, (2) the instability of starch dispersions in water, because a stock solution soon deposits a flocculent precipitate of retrograded starch, (3) starch gives along with iodine a water-insoluble complex, the formation of which precludes the addition of an indicator early in the titration, (4) the "drift" of the end-point, which is particularly marked when the solutions used are dilute. In the course of investigations of the glycolic ethers of starch and of its components, amylose and amylopectin, they found the derivative, the sodium salt of a starch glycolic acid, in which the ratio, glycolic acid units/glucose units, is approximately 1:10. The derivative, which they described conveniently as "sodium starch glycollate (1:10)" (SSG here after) has almost the same iodine-staining power as starch, itself, and possesses none of the disadvantages mentioned above. It is non-hygroscopic white powder which dissolves, with ease, in cold water to give a clear solution. Because the solutions are completely stable, no retrogradation occurs. Also, because the glycollate does not form a water-insoluble complex with iodine, the indicator may be added at any stage during titration, and the end-point is very sharp. On the other hand, we know that PVA (polyvinyl alcohol) ${ }^{7-13}$ and chitosan ${ }^{14}$ react with iodine to form a complex showing a color of bluish violet similar to that of the iodinestarch complex. We considered that PVA might be a more useful color reagent than starch or sodium glycolic acid, and we could determine a residual chlorine concentration of $0.1 \mathrm{ppm}$ using the PVA indicator. Preliminary experiments excluded the 

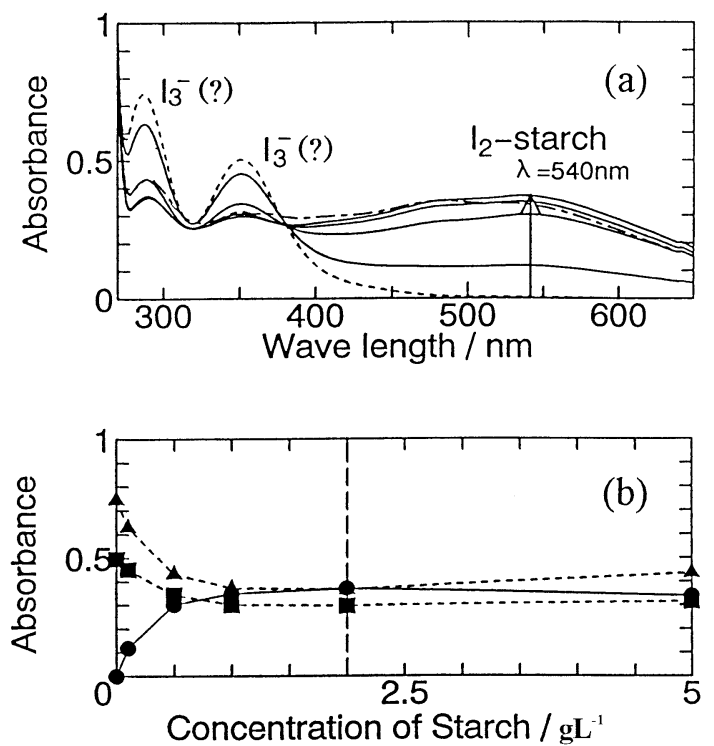

Fig. 1 Spectral change of the starch-iodine complex solutions due to a concentration increase (a), and the relationship between the iodine concentration and the absorbance of starch-iodine complex solutions at the respective absorption band $\left(\lambda_{\max }\right)(\mathrm{b}) . \quad\left[\mathrm{I}_{2}\right]=20$ $\mu \mathrm{mol} / \mathrm{L},[\mathrm{KI}]=10 \mathrm{~g} / \mathrm{L}$, at $20^{\circ} \mathrm{C}$. (a) $\cdots:$ : $[\mathrm{starch}]=0 \mathrm{~g} / \mathrm{L}$, , : [starch $]$ $=1.0-2.0 \mathrm{~g} / \mathrm{L}$, - $:$ : $[\mathrm{starch}]=5.0 \mathrm{~g} / \mathrm{L}$. (b) $\bullet, \lambda_{\max }=540 \mathrm{~nm} ; \mathbf{\square}, \lambda_{\max }$ $=350 \mathrm{~nm} ; \boldsymbol{\Lambda}, \lambda_{\max }=290 \mathrm{~nm}$.

possibility of chitosan as a color reagent because of its weak absorbance of the iodine complex. Although we investigated the above-mentioned three reagents, we did not use real residual chlorine solutions in the present work (as a basic study); instead, we only used iodine solutions to obtain accurate and precise experimental values, since small amounts of residual chlorine solutions are easily decomposed by ultraviolet light and a trace amount of heavy metals. Finally, we confirmed the superiority of PVA as a color indicator to the other two reagents, and will report on those results along with volumetric and spectrophotometric studies.

\section{Experimental}

\section{Materials}

Analytical-grade iodine, potassium iodide, sodium hydroxide, sodium thiosulfate and boric acid were commercially obtained from Wako Pure Chemical Co. Ltd. Partially saponificated PVA $(n=500,1000,1500,2000 ;$ s.d. $=86-90 \%$, ave. $88 \%)$, and perfectly saponificated PVA $(n=500,1000 ;$ s.d. $=96-$ $100 \%$, ave. 98\%) were also obtained from Wako Pure Chemical Co. Ltd., where $n$ and s.d. mean the degree of polymerization and the degree of saponification, respectively. Other partially saponificated PVA $(n=216 ;$ s.d. $=80 \%)$ and completely saponificated PVA ( $n=3522$; s.d. $=99 \%+)$, were commercially obtained from Aldrich Co. Ltd. Starch (potato, soluble) was obtained from Wako Pure Chemical Co. Ltd. It might be said here that PVA is one of the stereo-regular polymers, i.e., they have three kinds of tacticity: syndiotactic, isotactic, and atactic. However, we used only the atactic-type PVA, which can be commercially obtained as general products.

\section{Standard reagent solutions}

Standard solutions of iodine $\left(0.050 \mathrm{~mol} \mathrm{I}_{2} / \mathrm{L} \equiv 12.69 \mathrm{~g} \mathrm{I}_{2} / \mathrm{L}\right)$ with $\mathrm{KI}(10 \mathrm{~g} / \mathrm{L})$, iodine $\left(14.103 \mathrm{mmol} \mathrm{I}_{2} / \mathrm{L} \equiv 3759 \mathrm{mg} \mathrm{I} / 2 / \mathrm{L} \equiv\right.$
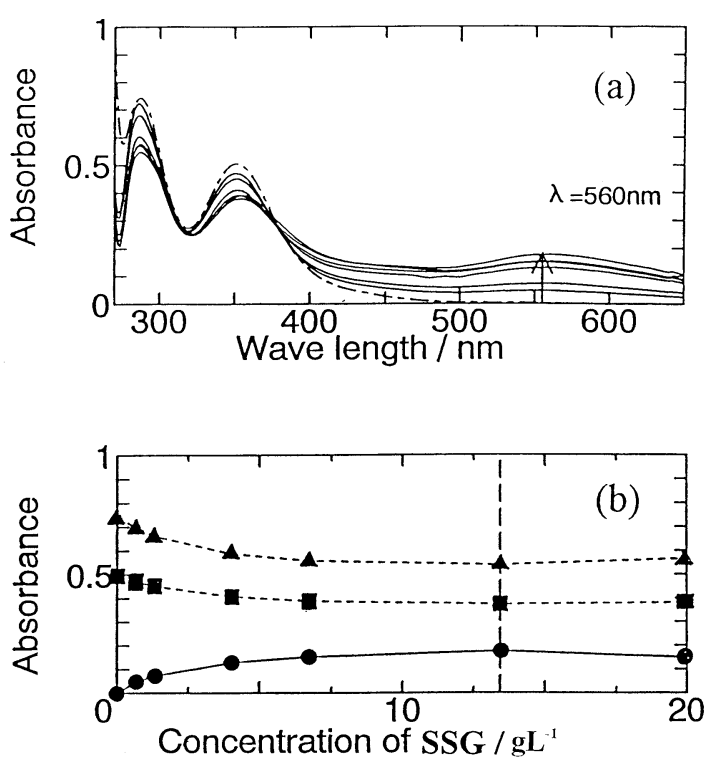

Fig. 2 Spectral change of the SSG-iodine complex solutions due to a concentration increase (a), and the relationship between the iodine concentration and the absorbance of SSG-iodine complex solutions at the respective absorption band $\left(\lambda_{\max }\right)(\mathrm{b}) .\left[\mathrm{I}_{2}\right]=20 \mu \mathrm{mol} / \mathrm{L},[\mathrm{KI}]=10$ $\mathrm{g} / \mathrm{L}$, at $20^{\circ} \mathrm{C}$. (a) $\cdots:[\mathrm{SSG}]=0 \mathrm{~g} / \mathrm{L},-$ : $[\mathrm{SSG}]=0.7-20 \mathrm{~g} / \mathrm{L}$. (b) $\lambda_{\max }=560 \mathrm{~nm} ; \boldsymbol{\square}, \lambda_{\max }=350 \mathrm{~nm} ; \boldsymbol{\Delta}, \lambda_{\max }=290 \mathrm{~nm}$.

$1000 \mathrm{mg} \mathrm{Cl} / \mathrm{L})$ with $\mathrm{KI}(10 \mathrm{~g} / \mathrm{L})$, KI (200 g/L), starch (10 g/L), PVA (100 g/L), boric acid $(50 \mathrm{~g} / \mathrm{L})$, and $\mathrm{Na}_{2} \mathrm{~S}_{2} \mathrm{O}_{3}(0.100 \mathrm{~mol} / \mathrm{L})$ were prepared using the above-mentioned reagents and used as stock solutions. They were diluted to appropriate concentrations before use.

\section{Apparatuses and glassware}

A ten-milliliter semi-micropipet was used for titrations. Volumetric pipets and flasks were obtained from Iwaki Glass Co. Ltd. To prepare sodium glycollate acid, Soxhlet's extractor was used according to reference. ${ }^{6}$

Electronic absorption spectra were measured using a Hitachi U-3210-type spectrophotometer. To maintain constant temperature, a thermostat (Coolnit CL-80; manufactured from Titec Co. Ltd.) was used.

\section{Procedures}

Titrations were carried out according to the Japanese Industrial Standard testing methods for industrial water JIS K 0101-1998 (JIS method hereafter). The JIS method describes (a) sample water containing an appropriate residual chlorine quantity $(0.1-7 \mathrm{mg})$ is taken into a $300 \mathrm{~mL}$ Erlenmeyer flask with a ground stopper. After pure water is added to a constant volume $(\mathrm{ca} .300 \mathrm{~mL})$, and $1 \mathrm{~g}$ of $\mathrm{KI}$ plus $5 \mathrm{~mL}$ of $(1+1)$ acetic acid is also added. Then, (b) the solution in the flask is shaken several times and let standing for $5 \mathrm{~min}$ in a dark place. (c) Liberated iodine is titrated with $10 \mathrm{mmol} / \mathrm{L}$ sodium thiosulfate, until the solution color becomes pale yellow; at this point, $1 \mathrm{~mL}$ of $1 \%$ starch is added as an indicator (violet blue), and then the titration is continued until the violet color blue disappears (at end point). (d) A blank test is also made using $100 \mathrm{~mL}$ of distilled water under the same conditions (a) - (c) as those of sample solutions. Electronic absorption spectra for iodinePVA, iodine-starch and iodine-SSG complexes were measured by the conventional spectrophotometric method.

We compared the capabilities or performances of PVA, starch, and its derivative SSG as color indicators on iodometry. 

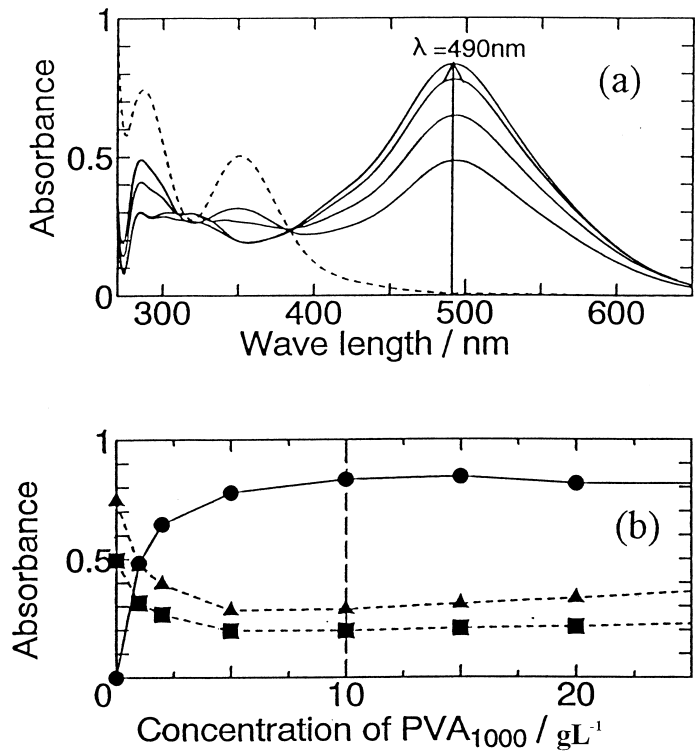

Fig. 3 Spectral change of the $\mathrm{PVA}_{1000}$-iodine complex solutions due to a concentration increase (a), and the relationship between the iodine concentration and the absorbance of $\mathrm{PVA}_{1000}$-iodine complex solutions at the respective absorption band $\left(\lambda_{\max }\right)$ (b). $\quad\left[\mathrm{I}_{2}\right]=20$ $\mu \mathrm{mol} / \mathrm{L},[\mathrm{KI}]=10 \mathrm{~g} / \mathrm{L}$, at $20^{\circ} \mathrm{C}$. (a) $\cdots:\left[\mathrm{PVA}_{1000}\right]=0 \mathrm{~g} / \mathrm{L},-$ $\left[\mathrm{PVA}_{1000}\right]=1.0-20 \mathrm{~g} / \mathrm{L}$. (b) $\bullet, \lambda_{\max }=490 \mathrm{~nm} ; \mathbf{\square}, \lambda_{\max }=350 \mathrm{~nm}$; $\Delta, \lambda_{\max }=290 \mathrm{~nm}$.

Special attention was paid to the detection limits or detection efficiencies, and two types of titrations were carried out: (1) detection limit by concentration and (2) detection limit by absolute weight

\section{Results and Discussion}

Absorption spectra of iodine-indicator complexes

Iodine-starch complex. The starch used was soluble starch (from potato). Figures 1(a) and (b) show the absorption spectra of the iodine-starch complex and the concentration dependence of the absorbance, respectively. It can be seen from the figure that the absorbance at the first band $\left(\lambda_{\max }=540 \mathrm{~nm}\right)$ increases along with an increase in the starch concentration, whereas the second $\left(\lambda_{\max }=350 \mathrm{~nm}\right)$ and third $\left(\lambda_{\max }=290 \mathrm{~nm}\right)$ bands decrease along with an increase in the starch concentration. The second and third bands can be ascribed to $\mathrm{I}_{3}{ }^{-}$ions (straight and bent types) ${ }^{8-10}$ On the other hand, the first band $\left(\lambda_{\max }=540\right.$ $\mathrm{nm}$ ) would correspond to the species of iodine-starch complex. The apparent simple chemical equilibria are shown as follows, although real iodine-starch complexes are complicated:

$$
\begin{aligned}
& \mathrm{I}_{2}+\mathrm{I}^{-} \rightleftharpoons \mathrm{I}_{3}{ }^{-}\left(\mathrm{K}^{15} \fallingdotseq 800(\mathrm{~mol} / \mathrm{L})^{-1} \text { at } 20^{\circ} \mathrm{C}\right) \\
& \mathrm{I}_{2}+\text { starch } \rightleftharpoons \mathrm{I}_{2}{ }^{-} \text {starch complex } \\
& \mathrm{I}_{3}{ }^{-}+\text {starch } \rightleftharpoons \mathrm{I}_{3}{ }^{-} \text {-starch complex }
\end{aligned}
$$

As shown in Fig. 1(b), under the condition $\left[\mathrm{I}_{2}\right]=20 \mu \mathrm{mol}(5.076$ $\mathrm{mg}) / \mathrm{L},[\mathrm{KI}]=10 \mathrm{~g} / \mathrm{L}$, at $20^{\circ} \mathrm{C}$, absorbance of iodine-starch complex at $540 \mathrm{~nm}\left(\lambda_{\max }\right)$ increases along with an increase in the starch concentration; however, it soon reaches a plateau at around a starch concentration of $1 \mathrm{~g} / \mathrm{L}$ and in more detail, it becomes nearly constant at around $1 \mathrm{~g} / \mathrm{L}$ and maximum at around $2 \mathrm{~g} / \mathrm{L}$, but then gradually decreases. A real iodine-starch

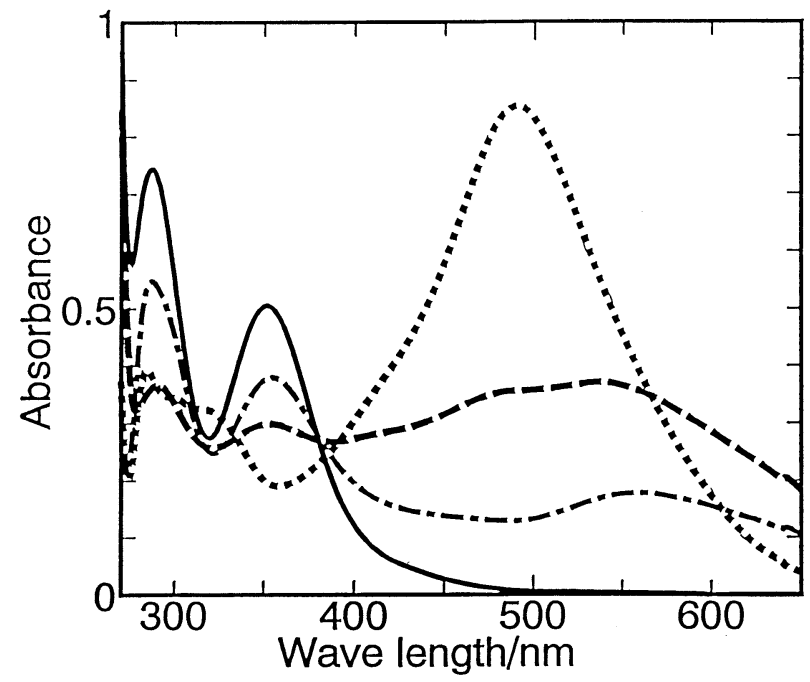

Fig. 4 Comparison of the electronic absorption spectra for starchiodine, SSG-iodine, and $\mathrm{PVA}_{1000}$-iodine complexes. $\left[\mathrm{I}_{2}\right]=20$ $\mu \mathrm{mol} / \mathrm{L},[\mathrm{KI}]=10 \mathrm{~g} / \mathrm{L}$, at $20^{\circ} \mathrm{C},[\mathrm{starch}]=5 \mathrm{~g} / \mathrm{L},[S S G]=10 \mathrm{~g} / \mathrm{L}$, $\left[\mathrm{PVA}_{1000}\right]=10 \mathrm{~g} / \mathrm{L},-\longrightarrow: \mathrm{I}_{2}$ (without indicator); ---: $\mathrm{I}_{2}$-starch complex $\left(\lambda_{\max }=540 \mathrm{~nm}\right) ;-$-.-.- : $\mathrm{I}_{2}-\mathrm{SSG}$ complex $\left(\lambda_{\max }=560 \mathrm{~nm}\right)$; .....: $\mathrm{I}_{2}-\mathrm{PVA}_{1000}$ complex $\left(\lambda_{\max }=490 \mathrm{~nm}\right)$.

complex seems more complicated, and there have been many investigations..$^{15-23}$

Iodine-SSG complex. In Fig. 2, the dependence of the concentration of iodine-SSG complex to absorbance is shown. The absorbance of the first band $\left(\lambda_{\max }=560 \mathrm{~nm}\right)$ corresponding to the $\mathrm{I}_{2}-\mathrm{SSG}$ complex increases along with an increase in the concentration, and becomes a constant value at more than $10 \mathrm{~g}$ $(\mathrm{SSG}) / \mathrm{L}$.

Iodine-PVA complex. PVA shows interesting properties which depend on the polymerization degree, saponification degree, and stereoselectivity. However, generally, only atactictype PVA is commercially obtained, and we used it in the present work.

Effect of PVA concentration. In Fig. 3, the electronic spectra of the iodine-PVA complex are shown. Figure 3(b) shows the dependence of the absorbance on PVA concentration. The first band $\left(\lambda_{\max }=490 \mathrm{~nm}\right.$ ) corresponds to the iodine-PVA complex. The absorbance increases along with an increase in the PVA concentration, forming a plateau at around more than $5 \mathrm{~g} / \mathrm{L}$. This limitation in the absorbance is apparently due to the iodine concentration $(20 \mu \mathrm{mol} / \mathrm{L})$.

Effect of the degree of polymerization. The dependence of the absorbance on the polymerization degree was examined. When the saponification degrees of the PVA used were constant ( $c$. s.d. $=88 \%$ ) it was found that the polymerization degree did not affect the shape of the spectra and the intensity of the absorbance.

Effect of the degree of saponification. The influence of the saponification degree on the iodine-PVA complex was studied over the range of 80 to $99 \%+$. We obtained the tendency that the higher is the saponification degree, the lower is the absorbance of the first band $\left(\lambda_{\max }=490 \mathrm{~nm}\right)$; for example, PVA completely saponificated (s.d. $=98 \%$ and $99 \%+$ ) gave no band corresponding to the $490 \mathrm{~nm}$ band (violet blue). Thus, the absorption spectrum of the iodine-PVA complex was found to be greatly affected by the saponification degree, i.e., the number of functional groups of acetyl affects it. For a further investigation, we tried to synthesize $c a .50 \%$ saponificated PVA by using PVA + acetyl chloride in acetic acid as the solvent, 

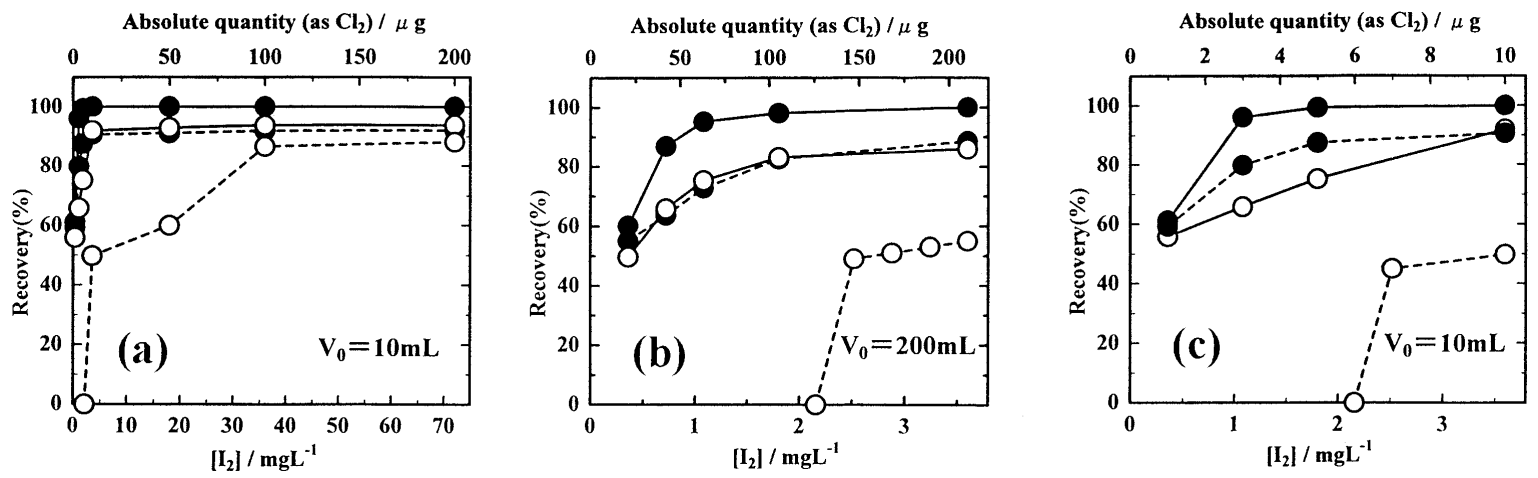

Fig. 5 Comparison of indicators (starch and $\mathrm{PVA}_{1000}$ ) on iodometry at a lower concentration region at the respective temperature (the relationships between residual chlorine* concentrations and their percent recoveries). *: in practical experiments, iodine solutions which are equivalent to prescribed residual chlorine concentrations were used. $\bigcirc: 1 \%$ starch $(1 \mathrm{~mL}), \bullet: 5 \% \mathrm{PVA}_{1000}$ [s.d. $=88 \%$ ] $(1 \mathrm{~mL})$, temperature:

$\left(0^{\circ} \mathrm{C}\right),---\left(20^{\circ} \mathrm{C}\right)$, sample volume: $V_{0}$.

because the hydrolysis of polyvinyl acetate using sodium hydroxide did not produce moderately saponificated PVA. The method of PVA acetylation seems to be better for our purpose, but we could not find an appropriate solvent to purify the target PVA, although the IR spectra show preferable saponification degrees. However, we might say here that complete saponificated PVA would give another absorption band $\left(\lambda_{\max }=\right.$ $640 \mathrm{~nm}$ ) when an appropriate concentration of boric acid is added. It must also be said that Miller and Bracken ${ }^{7}$ found the possibility of PVA being used as a color indicator, and reported this idea in their notes in 1951. There are several unsolved problems for iodine-PVA complexes, irrespective of extensive investigations..$^{7-13}$ We have carried out MO calculations on iodine-PVA complexes assuming that they are composed of polyiodide with straight or zigzag-type structures to interpret the reason for the color appearance of those bands around $490 \mathrm{~nm}$ $\left(\lambda_{\max }\right)$ or $640 \mathrm{~nm}\left(\lambda_{\max }\right)$; however, we could not obtain appropriate structures for the complexes until now. Hereafter, we will mainly use PVA of $88 \%$ saponification degree (average) with a polymerization degree of 1000 for convenience because of their plentiful supply.

\section{Comparison of absorption spectra of indicators}

Figure 4 shows the electronic spectra of iodine-starch, iodineSSG, and iodine-PVA $\mathrm{P}_{1000}$ complexes. Under this condition (i.e., $\mathrm{I}_{2}$ concentration is $20 \mu \mathrm{mol} / \mathrm{L}$ ), the absorbance of the iodinePVA complex band showed the highest value among the corresponding iodine-polymer complexes, iodine-starch and iodine-SSG complexes. Although Peat et al. ${ }^{6}$ recommend the usefulness of the SSG, it takes a longer preparation time and is cumbersome; we thus compare only iodine-PVA and iodinestarch complexes as indicators on iodometric titration in the following.

\section{Comparison of the indicators in the low concentration region}

As is well known, the stabilities of the PVA-iodine or starchiodine complexes are temperature dependent (the lower, the more stable), ${ }^{21}$ and we thus chose experimental temperatures of $20^{\circ} \mathrm{C}$ (standard temperature) and $0^{\circ} \mathrm{C}$ (lower temperature) from a practical point of view. Figures 5(a) - (c) show the results of iodometric titrations for PVA and starch indicators. According to the JIS method (K-0101), measurable quantities for a residual chlorine solution are $0.1-7 \mathrm{mg}$ (absolute), which correspond to iodine quantities of $0.36-25 \mathrm{mg}$. We carried out two kinds of experiments: whether the detection limit is principally determined by absolute quantity or concentration. In Fig. 5(b), experimental results with sample volume of $200 \mathrm{~mL}$ were shown. At $0^{\circ} \mathrm{C}$, both PVA and starch give more than $80 \%$ recovery (detection efficiencies) in the region $1.8-3.6 \mathrm{mg} \mathrm{I}_{2} / \mathrm{L}$ $(360-720 \mu \mathrm{g})$, especially, PVA gives almost $100 \%$ recovery. Even at $0.36 \mathrm{mg} \mathrm{I}_{2} / \mathrm{L}(72 \mu \mathrm{g})$, which correspond to $0.1 \mathrm{mg} \mathrm{Cl}_{2} / \mathrm{L}$ $(20 \mu \mathrm{g})$, both indicators gave more than $50 \%$ recoveries at $0^{\circ} \mathrm{C}$. Here, the percentage recoveries were determined by using the ratio of two values, i.e., experimentally obtained value (titration volume of the standard solution of sodium thiosulfate and the concentration) to the theoretically obtained one (added volume of iodine and the concentration). However, as shown in the figure, the detection curve of PVA indicator at $20^{\circ} \mathrm{C}$ gave nearly the same detection curve as the starch indicator at $0^{\circ} \mathrm{C}$. On the other hand, the detection curve for starch at $20^{\circ} \mathrm{C}$ gave 50 to $55 \%$ at best around the concentration range $2.5-3.6 \mathrm{mg} \mathrm{I}_{2} / \mathrm{L}$ $(500-720 \mu \mathrm{g})$, also, at concentrations lower than $2.1 \mathrm{mg} \mathrm{I} / \mathrm{L}$ $(420 \mu \mathrm{g})$ no coloring was observed.

While, in case of a sampling volume of $10 \mathrm{~mL}$, both PVA and starch detected more than $80 \%$ in the range of $36-72 \mathrm{mg} \mathrm{I}_{2} / \mathrm{L}$ $(360-720 \mu \mathrm{g})$ at $0^{\circ} \mathrm{C}$ and $20^{\circ} \mathrm{C}$, as shown in Fig. 5(a). However, in the concentration range of less than $36 \mathrm{mg} \mathrm{I}_{2} / \mathrm{L}$ $(360 \mu \mathrm{g})$, starch at $20^{\circ} \mathrm{C}$ showed a rapid lowering of the detection efficiency and at $3.6 \mathrm{mg} \mathrm{I}_{2} / \mathrm{L}(36 \mu \mathrm{g})$ the detection efficiency was around $50 \%$. This corresponds to a detection efficiency of $3.6 \mathrm{mg} \mathrm{I}_{2} / \mathrm{L}(720 \mu \mathrm{g})$ in Fig. 5(b) (sampling volume of $200 \mathrm{~mL}$ ). If titration is carried out at $0^{\circ} \mathrm{C}$, and a detection efficiency of $50 \%$ is permitted (appropriate corrections are presumed), both PVA and starch can be used as indicators until $0.36 \mathrm{mg} \mathrm{I}_{2} / \mathrm{L}(3.6 \mu \mathrm{g})$, which correspond to $0.1 \mathrm{mg} \mathrm{Cl}_{2} / \mathrm{L}(1 \mu \mathrm{g})$ as shown in Fig. 5(c). A systematic correction method in the low concentration region of iodine or residual chlorine using a PVA indicator will be reported in a following paper. The above results indicate that the detection limit is mainly controlled by the concentration, not by the absolute contents on iodometry using a titration method, and that the titration efficiency $v s$. the (iodine) concentration curves of PVA at $20^{\circ} \mathrm{C}$ is nearly the same as those of starch at $0^{\circ} \mathrm{C}$. Finally, we can conclude that partially saponificated PVA should be an excellent color indicator compared with the conventional starch indicator on iodometry titrations. 


\section{Acknowledgements}

The authors wish to thank Miss Maya Matsumoto and Miss Yuko Hayashi for their assistance with iodometry experiments.

\section{References}

1. J. Ramph, M. C. Nienaber, and H. J. De Bruyn, Mater. Perform., 1999, 38, 48.

2. K. K. Satpathy, Bull. Electrochem., 1999, 15, 143.

3. J. Philip, Off. Proc.-Int. Water Conf. VO: 59th, 1998, 415.

4. "Standard Methods for the Examination of Water", Ministry of Health and Welfare, Public Health Bureau, Water Supply and Environmental Sanitation Department, 1993, Japan Water System Association, Tokyo.

5. K 0101, "Testing methods for industrial water", 1998 Japanese Industrial Standards Committee, Tokyo.

6. S. Peat, E. J. Bourne, and R. D. Thrower, Nature, 1947, $159,810$.

7. S. A. Miller and A. Bracken, J. Chem. Soc., 1951, Part 3, 1933.

8. R. E. Buckles, J. P. Yuk, and A. I. Popov, J. Am. Chem. Soc., 1952, 74, 4379.

9. M. B. Robin, J. Chem. Phys., 1964, 40, 3369.

10. H. Djojosubroto, Y. Tanizaki, and T. Hoshi, Bull. Chem.
Soc. Jpn., 1970, 43, 3025

11. H. Takamiya, Y. Tanahashi, T. Matsuyama, T. Tanigami, K. Yamaura, and S. Matsuzawa, J. Appl. Polym. Sci., 1993, 50, 1807.

12. Y. Choi and K. Miyasaka, J. Appl. Polym. Sci., 1994, 51, 613.

13. A. Tanioka, Kobunshi Kako, ("Polymer Processing": Review for "Reactions between PVA and Iodine" in Japanese), 1994, 43, 386.

14. Y. Shigeno, K. Kondo, and K. Takemoto, J. Appl. Polym. Sci., 1980, 25, 731.

15. G. A. Gilbert and J. V. R. Marriott, Trans. Faraday Soc., 1948, 44,84 .

16. R. R. Baldwin, J. Am. Chem. Soc., 1944, 66, 111

17. R. E. Rundle, J. F. Foster, and R. R. Baldwin, J. Am. Chem. Soc., 1944, 66, 2116.

18. R. S. Stein and R. E. Rundle, J. Chem. Phys., 1948, 16, 195.

19. S. Ono, S. Tsuchihashi, and T. Kuge, J. Am. Chem. Soc., 1953, 75, 3601 .

20. H. Kuhn, J. Chem. Phys., 1949, 17, 1198

21. Y. Hoshino, Denki Kagaku, 1949, 18, 6.

22. B. Latte, A. Kienast, C. Bruhn, A. Loidl, and H. Homborg, J. Porphyrins and Phthalocyanines, 1997, 1, 267.

23. M. E. Heyde, L. Limai, R. G. Kilponen, and D. Gill, J. Am. Chem. Soc., 1972, 94, 5222. 